\title{
A ATIVIDADE MANDIOQUEIRA E A FORMAÇÃO TERRITORIAL DO AGRESTE POTIGUAR
}

\author{
Diego Salomão Candido de Oliveira Salvador \\ Mestre em Geografia pela UFRN. E-Mail: diegosalomao84@hotmail.com; \\ diegolisse@yahoo.com.br
}

\section{RESUMO}

Com a concepção de que o território não deve ser entendido apenas como um limite político-administrativo, mas também como um espaço que é usado pela sociedade, pelo poder público e pelas empresas e que tem, dessa maneira, importância na formação social dos povos, buscamos, no presente artigo, apreender a participação da atividade mandioqueira (cultivo da mandioca com a sua transformação em farinha e em outros derivados) no processo de formação territorial do Agreste Potiguar, evidenciando também, de maneira breve, alguns aspectos que marcam a modernização dessa atividade no referido território. Destacamos que o processo de formação do território do Agreste Potiguar ancorou-se nas atividades de criação de gado, cultivo do algodão e culturas de subsistência (mandioca, feijão, milho etc.), por meio das quais o povo agrestino reproduziu-se socialmente e organizou seu território. Das culturas de subsistência, aquela que possuía importância para os agrestinos durante um maior período no ano era a mandioqueira, justamente por ser a mandioca uma planta resistente e que pode ser cultivada durante longos e variados ciclos. Assim sendo, a partir da realização de pesquisas bibliográfica e empírica analisamos o desencadear pretérito da atividade mandioqueira no Agreste Potiguar, asseverando que tal atividade exerceu a função primordial de cultura de subsistência no processo de formação do território em baila, apresentando-se, assim, importante para a sobrevivência de grande parte dos agrestinos. Por fim, evidenciamos, de maneira breve e preliminar, que a atividade mandioqueira vem passando por um processo de modernização no Agreste Potiguar, desde a década de 1980. Essa modernização traz à tona mudanças nas técnicas utilizadas no cultivo e na transformação da mandioca, nas relações de trabalho entre produtores de mandioca - trabalhadores e donos de casas ou de indústrias de farinha e no uso atual do território do Agreste Potiguar. Destarte, frisamos que essas transformações necessitam ser analisadas de maneira detalhada, em um próximo artigo, devido aos limites estabelecidos pelo objetivo do presente trabalho.

PALAVRAS-CHAVE: Atividade mandioqueira. Formação territorial. Agreste Potiguar.

\section{LA ACTIVIDAD MANDIOQUERA Y LA FORMACIÓN TERRITORIAL DEL AGRESTE POTIGUAR}

\section{RESUMEN}

Con la idea de que el territorio no debe entenderse sólo como límites políticoadministrativos, sino también como un espacio que es utilizado por la sociedad, por el público y las empresas y tiene, por lo tanto, importancia en la formación de las personas, 
buscamos, en este artículo, aprehender la contribución relativa de la actividad Mandioquera (cultivo de la yuca y su transformación en derivados de la harina y otros) en el proceso de formación territorial del Agreste Potiguar, muestrando también, brevemente, algunos aspectos que hacen a la modernización de esta actividad en dicho territorio. Resaltamos que el proceso de formación del territorio del Agreste Potiguar echo anclas en las actividades de ganado, algodón y cultivos de subsistencia (yuca, frijoles, maíz, etc.), mediante el cual la gente agrestina reproduce socialmente y organizado su territorio. De los cultivos de subsistencia, lo que tenía importancia para los agrestinos durante un largo período en el año fue la actividad mandioquera, precisamente porque la yuca es una planta resistente, y puede ser cultivada durante largos y variados ciclos. Así, desde la realización de investigaciones bibliográficas y estudios empíricos, analizamos el pasado de la actividad mandioquera en el Agreste Potiguar, aseverando que esta actividad sirvió como cultivo de subsistencia primaria en el proceso de formación del territorio en cuestión, importante para la supervivencia de la mayoría de los agrestinos. Por último, señalamos, de manera breve y preliminar, que la actividad mandioquera está sufriendo un proceso de modernización en Agreste Potiguar, desde la década de 1980. La modernización pone de manifiesto los cambios en las técnicas utilizadas en el cultivo y procesamiento de la yuca, la relación de trabajo entre los productores de yuca - trabajadores y propietarios de viviendas o de las industrias de harina, y el uso actual del territorio del Agreste Potiguar. Por lo tanto, hacemos ahínco en que estos cambios deben ser analizados en detalle en un artículo próximo, debido a los límites establecidos por el objetivo de este trabajo.

PALABRAS-CLAVE: Actividad mandioquera. Formación territorial. Agreste Potiguar. 


\section{A ATIVIDADE MANDIOQUEIRA E A FORMAÇÃO TERRITORIAL DO AGRESTE POTIGUAR}

\section{INTRODUÇÃO}

O presente artigo tem o objetivo de apreender a participação da atividade mandioqueira (cultivo e transformação da mandioca em farinha e outros derivados) no processo de formação territorial do Agreste Potiguar (figura 01), evidenciando também, de maneira breve, alguns aspectos que marcam a modernização dessa atividade no referido território. Vale evidenciar que, de acordo com as concepções de Santos (1996), afirmamos (SALVADOR, 2009) que o território é uma forma impura, um híbrido, que constantemente é alterado. O que vale numa análise social não é o território em si, mas o seu uso. $\mathrm{O}$ território por si só constitui-se apenas de formas. O território usado é perpassado por objetos e ações, sendo sinônimo de espaço habitado, de espaço humano.

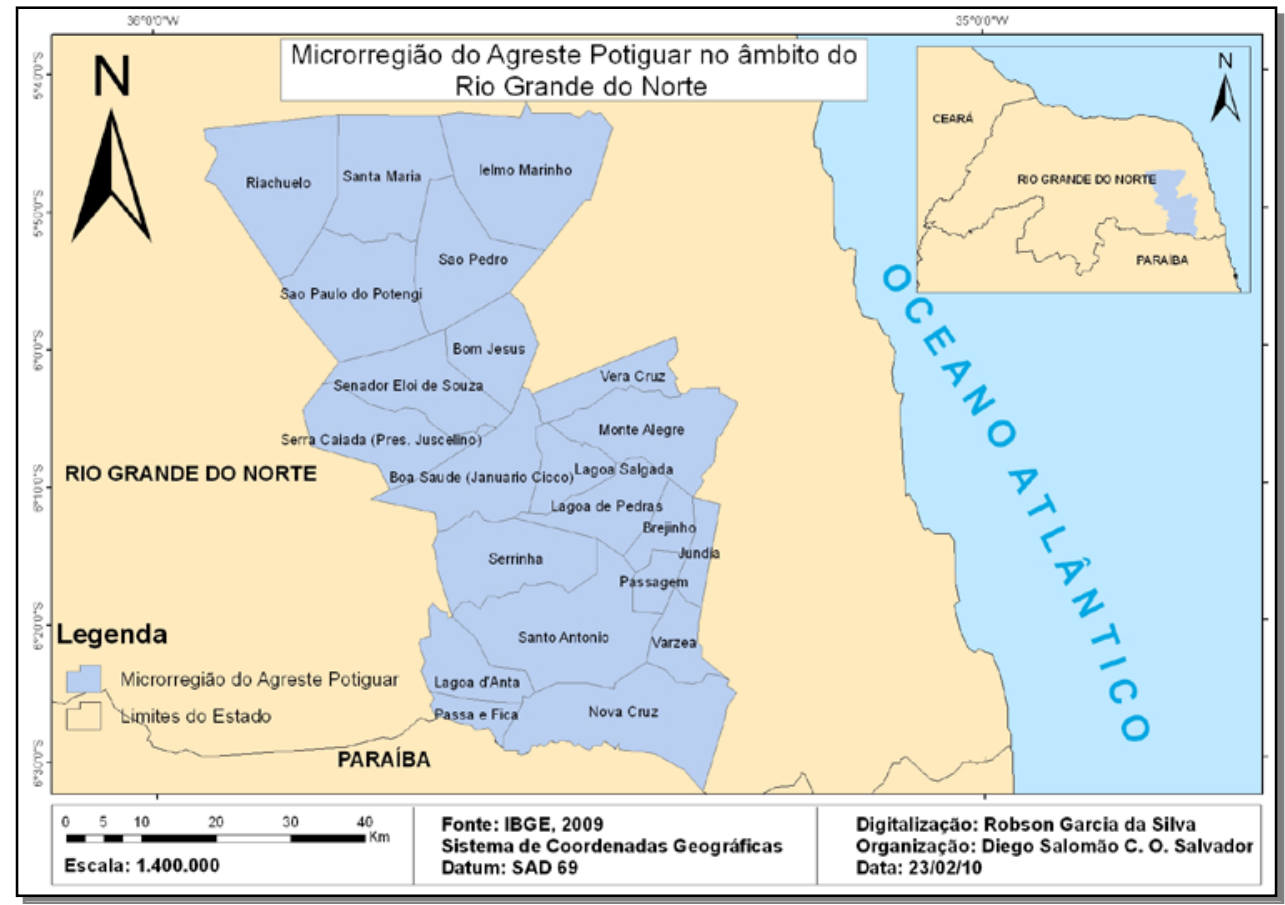

Figura 01: Agreste Potiguar no âmbito do Rio Grande do Norte Fonte de dados: IBGE, 2007.

O território é a dimensão do espaço marcada pela ideia de domínio, de apropriação. Essa dimensão liga-se à categoria poder, que pode ser exercida tanto pelo Estado e pelas grandes empresas quanto pela sociedade civil. O território não deve ser entendido apenas como um limite político-administrativo, mas também como um espaço usado pela sociedade, pelo poder público e pelas empresas. Tem, pois, importância na formação social dos povos (SANTOS, 1996).

Destarte, seguindo a perspectiva teórico-metodológica da Geografia Nova (Id., 2004), acreditamos que é por meio da formação social que se cria e recria, constantemente, uma estrutura espacial. Esse processo é ancorado nas dimensões econômica, social, política, cultural, dentre outras. A formação social é o instrumento legítimo de explicação da 
sociedade e do seu espaço (Ibid.). Tal instrumento é mais do que a expressão econômica da história: é o conceito que abarca a totalidade da vida social (Id., 1979).

Coadunamos com Santos (2004) quando ele diz que trabalhar com a noção de formação social é imprescindível aos estudos geográficos, devido essa categoria possibilitar que seja dada atenção ao estudo das sociedades humanas em sua obra permanente de (re)construção dos espaços (ou uso dos territórios) através das diversas instâncias da produção. Isso também é dito por Lefebvre (2000), quando assevera que a produção do espaço não se realiza num dia, tratando-se de um processo. Além disso, o sociólogo francês prossegue afirmando que uma revolução social deve envolver uma nova produção do espaço. Em outras palavras, defende que a transformação da sociedade envolve, necessariamente, a metamorfose do espaço.

Considerando o espaço como um fato histórico, afirmamos que para que haja a sua compreensão é necessário atentar para a história da sociedade organizando o seu espaço, isto é, construindo-o e reconstruindo-o (SANTOS, 2004, 1999, 1997). Não há história que possa ser escrita fora do espaço, e não há sociedade a-espacial. Daí haver a possibilidade de denominar a noção de formação social de "formação socioespacial” (Id., 1979). Contudo, é necessário que se diga que tal denominação só deve ser usada quando a análise for referente a formação social de Estados-Nação. Quando a análise for acerca de escalas regional, estadual ou municipal pode-se usar a denominação "formação territorial”"

A partir desse entendimento acerca do conceito de território e da noção de formação socioespacial, passamos, agora, a meditar sobre a atividade mandioqueira e a formação territorial (uso pretérito do território) do Agreste Potiguar. Após a realização dessas reflexões, teceremos considerações finais, fazendo referência, de maneira breve, a modernização de tal atividade.

\section{ATIVIDADE MANDIOQUEIRA E FORMAÇÃO TERRITORIAL: REFLEXÕES SOBRE O AGRESTE POTIGUAR}

O Agreste Potiguar, segundo dados do IBGE (2009)² , é o território potiguar em que mais se produz mandioca, planta que marca esse território desde a sua formação. De acordo com Melo (1980), o Agreste Potiguar vem exercendo funções socioeconômicas imprescindíveis para o cenário estadual. Esse território vem se destacando pela produção de gêneros alimentícios, de matérias-primas e de mercadorias para o abastecimento de outros territórios, dentre os quais o da capital estadual. Por isso, “[...] está fora de dúvida que sua participação na economia estadual lhe assegura um papel de singular importância no contexto territorial do Rio Grande do Norte” (Ibid., p. 41).

O processo de formação do território do Agreste Potiguar ancorou-se nas atividades de criação de gado, cultivo do algodão e culturas de subsistência (mandioca, feijão, milho etc.), por meio das quais o povo agrestino reproduziu-se socialmente e organizou seu território.

\footnotetext{
${ }^{1}$ Em outro artigo (SALVADOR, 2009), colocamos em baila abordagens mais detalhadas sobre a discussão das noções de "formação social” e "formação socioespacial ou territorial”.

2 Esses dados indicam que, em 2008, se produziu no Agreste Potiguar 48\% da produção estadual de mandioca, que foi de 572.949 toneladas.
} 
A pecuária teve importância fundamental para o processo de interiorização da ocupação do território do Rio Grande do Norte. Foi através da criação de gado que se fomentou, inicialmente, a organização dos territórios do Agreste e do Sertão norte-rio-grandenses. Outra atividade importante foi a algodoeira. O desencadeamento dessa atividade proporcionou a intensificação da ocupação do Agreste e do Sertão bem como uma melhor articulação desses territórios com o litoral, por meio das rodovias e das ferrovias implementadas para atender às necessidades dessa atividade.

Consorciada a essas atividades, foram realizadas as culturas para a subsistência ${ }^{3}$ do povo. Os agrestinos plantavam, sobretudo, mandioca, feijão e milho, visando garantir sua sobrevivência. De acordo com Linhares e Teixeira Silva (1981), o consorciamento de produtos sempre foi proveitoso para os agricultores, sobretudo para os que dispunham de pequenas propriedades: primeiro, vinha o milho e o feijão; depois, o algodão; e, por último, a mandioca, a senhora do campo.

Segundo Linhares e Teixeira Silva (Ibid.), as plantações de subsistência também eram realizadas, separadamente, em algumas terras não ocupadas por produtos destinados à exportação (cana-de-açúcar e algodão). Segundo esses autores, no período colonial não havia mecanismos de vigilância ou repressão, por parte do Estado português, que impedissem a ocupação intrusiva de terras virgens, sobretudo as localizadas em territórios longínquos, as quais não eram usadas para as plantations. Desse modo, alguns homens livres pobres e escravos fugidos estabeleciam suas roças ao longo de rios e/ou de caminhos em terras não usadas. O estabelecimento dessas roças era fato conhecido pela Coroa, que o considerava como uma retaguarda da ocupação branca do litoral.

Asseveramos que a pecuária e o algodão foram atividades com importância econômica para os agentes dominantes no processo de formação do território agrestino. Os latifundiários e os detentores dos meios de produção garantiam sua renda e o exercício do poder sobre o povo por meio dessas atividades. Em contrapartida, o cultivo da mandioca, do milho e do feijão teve importância social no desenrolar desse processo, isso por ser realizado com o objetivo de garantir a subsistência e/ou a sobrevivência da maioria das pessoas.

Das culturas de subsistência, aquela que possuía importância para os agrestinos durante um maior período no ano era a mandioqueira, justamente por ser a mandioca uma planta resistente e que pode ser cultivada durante longos e variados ciclos. Assim sendo, neste trabalho as atenções são dadas à atividade mandioqueira, por ela ter sido importante para a sobrevivência dos agrestinos e para a formação territorial do Agreste Potiguar bem como por ela vir passando por mudanças que impactam no uso atual do território em tela.

\footnotetext{
${ }^{3}$ Furtado (1984) defende que a economia de subsistência do Nordeste sempre foi precária, constituindo o elemento básico do problema econômico nacional em épocas posteriores. Esse é um pensamento meramente econômico, que desconsidera a importância dos cultivos de subsistência para a sobrevivência do homem nordestino, sobretudo do pobre. Para nós, o problema econômico-social do Brasil passa muito mais pela questão das graves desigualdades que marcam a realidade do país do que pelo desencadeamento de culturas de subsistência, as quais nos parecem que, ao invés de problema, devem ser compreendidas como solução para muitos trabalhadores brasileiros, especificamente os nordestinos.
} 
Para compreender como se dava a atividade mandioqueira no Agreste Potiguar até a década de 1980, quando essa atividade começou a ser modernizada, além de realizarmos pesquisa bibliográfica (MELO, 1980; ANDRADE, 1986; MONTEIRO, 2008), conversamos com agrestinos que pudessem fornecer informações importantes acerca do desencadear pretérito dessa atividade no referido território. As conversas ocorreram de maneira semiestruturada ${ }^{4}$, no período de março a maio de 2008, e foram gravadas. Durante essas conversas, dissemos às pessoas com as quais conversamos que não era necessário que elas se identificassem, o que as deixou mais à vontade para fornecerem informações detalhadas sobre a atividade em foco. Assim, identificamos esses interlocutores, no decorrer do trabalho, de acordo com as funções que exerciam, no período de realização da pesquisa, na atividade mandioqueira. Vale frisar que, por meio dessas conversas, tivemos acesso a informações sobre: o que era produzido no Agreste Potiguar; como se produzia a mandioca e como ela era transformada em farinha e outros derivados; como se davam as relações de trabalho nas casas de farinha; o que era feito com a mandioca e a farinha produzidas; dentre outros aspectos.

A partir dessas conversas, podemos afirmar que, no Agreste, se produzia o algodão (uma cultura mais comercial) e alimentos destinados à subsistência do povo (feijão, milho, mandioca, inhame, fava, dentre outros) bem como se criava gado, sobretudo, o leiteiro. Dos alimentos destinados à subsistência, segundo agricultores agrestinos, aquele que se destacava era a mandioca. Isso devido a alguns motivos, os quais são explicitados com as palavras de interlocutores das conversas:

\begin{abstract}
Pra mim, é uma planta que tem muita importância. Ela dá alimento à vida humana, aos animais. Vai para todo estado que precisar de farinha, através de transporte. A maior renda que existe aqui é de plantação de mandioca. Tirando isso, não tem quase nada. Toda vida ela teve importância. A farinha é fundamental. A mandioca é fundamental. Antigamente, se uma mesa não tivesse farinha, pra muita gente não tinha nada. Hoje tem o arroz. Mas naquele tempo não tinha arroz, tinha farinha. Ave Maria, a farinha e o feijão era a maior base da alimentação, principalmente da classe pobre!

Da mandioca, o cara faz a farinha de mandioca mole, pra fazer o bolo, a tapioca, o beiju, o cuscuz. Tudo isso é muito produtivo e é gostoso demais.

A plantação de mandioca é uma renda certa. Você planta o feijão e perde, às vezes, com o Sol, às vezes com a chuva. Você planta o milho e falta chuva e você perde. A roça de mandioca você não perde (produtor de mandioca de Bom Jesus).
\end{abstract}

Fazer farinha, tirar a goma, fazer comida pro gado. Não se perdia nada não. A casca, a maniva moída, tudo usava (produtor de mandioca de Elói de Souza).

A mandioca era plantada por produtores que, na maioria das vezes, tinham terra própria ou tinham acesso a um pedaço de terra sem ter que pagar nada por isso. Devido essa planta ser marcada por longo período de cultivo, no caso específico do Agreste Potiguar, o cultivo da mandioca era realizado no período de 1,5 a 2 anos, não oferecia, assim, vantagens para o arrendamento de terras para nelas ser feito tal cultivo.

As terras eram arrendadas em sistema de meação ou através de um sistema em que o produtor pagava, ao dono da terra, no final da produção, um preço estipulado. Devido ao

\footnotetext{
${ }^{4}$ As conversas foram semiestruturadas devido a termos definido algumas perguntas que provocassem outras nos momentos das conversas, permitindo a obtenção de informações detalhadas.
} 
longo ciclo de cultivo, nem o produtor nem o dono da terra se interessavam pelo roçado de mandioca no sistema de arrendamento: o primeiro sempre tinha prejuízo ao final da produção, quando deveria ceder metade do que fora produzido ao dono da terra, ou pagar um valor, que aumentava no decorrer do processo produtivo, devido aos empréstimos que fazia, geralmente, ao dono da terra, para manter o mandiocal e, até mesmo, para adquirir alimentos para sua subsistência; já o segundo só iria ter rentabilidade com sua terra após um período longo de, no mínimo, 1,5 ano, o que não lhe interessava: “a mandioca não tinha futuro para ser plantada em terra alheia” (produtor de mandioca de Serra Caiada).

Mas, não podemos afirmar que, em hipótese alguma, não havia arrendamento de terra para o estabelecimento de roçado de mandioca: "tinha gente que arrendava terra, porque não tinha onde trabalhar" (produtor de mandioca de Elói de Souza). O cultivo da mandioca ocorria em pequenas faixas de terra, sendo destinado à subsistência do povo e ao fornecimento de alimento para o gado. Havia relações em que donos de pequenas propriedades de terra arrendavam, por preços acessíveis, parte de sua propriedade a produtores sem terra, para que cultivassem roçados (de milho, feijão, mandioca): "era mais fácil conseguir roçado com os pequenos proprietários do que com os grandes” (produtor de mandioca de Serra Caiada). O arrendamento, como dissemos, também poderia ser feito por sistema de meação ou de pagamento de um valor, estipulado pelo dono da terra, ao final da produção. No Agreste Potiguar, esse valor era de, geralmente, $20 \%$ do que fora produzido. Todavia, segundo um produtor de mandioca de Bom Jesus, os arrendamentos aconteciam, em sua grande maioria, pelo sistema de meação, isso porque era mais vantajoso para o dono da terra.

O roçado da mandioca era estabelecido de maneira consorciada com outros roçados (de milho e feijão, sobretudo) e com atividades de cunho comercial (pecuária e algodão). Em relação ao consorciamento com a atividade da pecuária, podemos dizer que da mandioca, sobretudo de sua casca e da maniva, se fazia ração para alimentar o gado. Os grandes proprietários de terra, que geralmente eram criadores de gado, não tinham muito interesse em plantar mandioca. Contudo, se interessavam em adquirir a mandioca produzida por agricultores, em sua maioria, pequenos proprietários, para servir de alimento para seu gado.

No tocante ao consorciamento da mandioca com o milho, o feijão e o algodão, podemos dizer que alguns produtores plantavam roçados com fileiras alternadas de milho, feijão e mandioca, cultivando também, ao lado dessas fileiras, o algodão. Com o cultivo algodoeiro, os produtores garantiam sua renda, basicamente, durante três meses do ano. Após isso, o produto que supria as necessidades dos produtores durante a maior parte do ano era a mandioca. Destaca-se que o milho e o feijão são também culturas com período temporário bastante definido (geralmente, ambas são cultivadas apenas em três meses do ano), além de serem frágeis diante das adversidades edafoclimáticas, diferentemente da mandioca.

O cultivo da mandioca durava cerca de 1,5 a 2 anos. O plantio era feito, assim como hoje, no período de chuvas (geralmente, de janeiro até março). A colheita era realizada, assim como hoje, geralmente, no período de agosto a dezembro do ano posterior àquele em que houvera o plantio. Contudo, por ser uma planta bastante resistente, havia produtores que a colhiam posteriormente a esse período, no máximo até o mês em que se completavam os 24 meses de cultivo. Em suma, dizemos que a cultura mandioqueira sempre foi 
caracterizada por sua flexibilidade em relação ao plantio e à colheita ${ }^{5}$. Havia produtores que colhiam parte da produção no período de agosto a dezembro, deixando outra parte para ser colhida posteriormente. Isso garantia aos produtores subsistência e renda na maior parte do ano.

O cultivo mandioqueiro era realizado, geralmente, sem a utilização de adubos e/ou de defensivos agrícolas. Devido a isso, o ciclo de produção era longo: durava até 2 anos. Segundo um produtor de mandioca de Bom Jesus, a utilização de adubos não era necessária porque as terras, antigamente, eram mais férteis, possibilitando rentabilidade de até 12 toneladas de mandioca por hectare. Hoje, com as terras cansadas, isto é, após muita utilização, e com a propagação da lógica da modernização capitalista, os produtores vêm utilizando cada vez mais adubos, inclusive os químicos, com o objetivo de obterem maior rentabilidade no menor tempo possível. Não podemos deixar de afirmar que, de acordo com um produtor de mandioca de Boa Saúde, alguns produtores utilizavam antigamente adubo orgânico (de gado) nas plantações, mas isso não era predominante: acontecia apenas em alguns momentos e era realizado apenas por alguns produtores.

O processo de cultivo da mandioca consistia nos seguintes procedimentos (figura 02): 1) desmatava-se a terra; 2) cortava-se a terra, manualmente ou com a utilização do boi manso; 3) plantava-se a maniva, principalmente por meio de trabalho familiar; 4) o próprio produtor, juntamente com sua família, realizava limpas no roçado; 5) colhiam-se as raízes, principalmente por meio de trabalho familiar; 6) separava-se parte da maniva para se plantar outro mandiocal, sendo o restante vendido a fazendeiros para a fabricação de ração para o gado; e 7) transportavam-se, geralmente em jumentos, as raízes para transformação nas casas de farinha ou procurava-se fornecê-las a criadores de gado, para fabricação de ração animal.

\footnotetext{
${ }^{5}$ Esse pressuposto ainda é válido para o momento atual da atividade mandioqueira no Agreste Potiguar. Isso fica evidente quando analisamos os dados do censo agropecuário de 2006 do IBGE (2009), os quais mostram que a mandioca é plantada e colhida, no Agreste Potiguar, durante todos os meses do ano, havendo, logicamente, meses (janeiro, fevereiro e março) em que o plantio é elevado, assim como meses (agosto, setembro, outubro, novembro e dezembro) em que a colheita é elevada.
} 


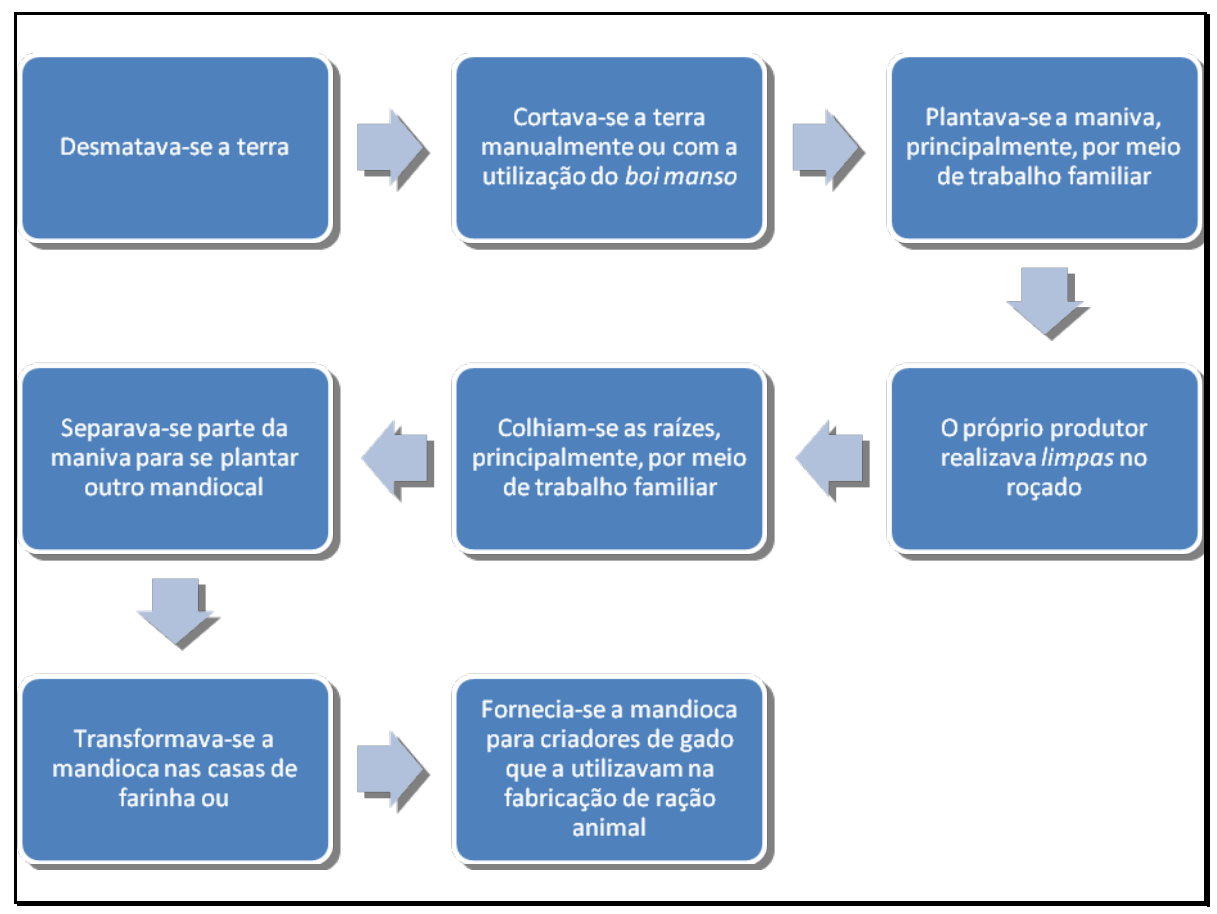

Figura 02: Como ocorria o cultivo da mandioca no Agreste Potiguar, até a década de 1980

Elaboração: Diego Salomão C. O. Salvador, 2008.

A mandioca produzida era, na maior parte, transformada em farinha e em outros derivados (bolos, beiju, cuscuz etc.), que iriam servir para a alimentação das pessoas. Também se utilizava a mandioca seca, a casca e a maniva para se preparar ração para o gado. A transformação da mandioca em farinha e outros derivados era realizada nas residências dos agrestinos ou nas casas de farinha.

O processo de transformação domiciliar da mandioca consistia nos seguintes procedimentos (figura 03): 1) descascava-se a mandioca; 2) lavavam-se as raízes descascadas; 3) ralava-se, manualmente, a mandioca para transformá-la em massa; 4) prensava-se a massa com um pano, para retirar o máximo possível da manipueira; 5) peneirava-se a massa, a fim de enfarinhá-la; 6) torrava-se a massa enfarinhada em um caco (vasilha rústica) colocado sobre o fogo; e 7) armazenava-se a farinha, a qual seria utilizada para o consumo familiar. Parte da massa não era transformada em farinha, mas em bolos, cuscuz, beiju etc. Esse processo gerava alimentos que garantiam a subsistência dos indivíduos da família. 


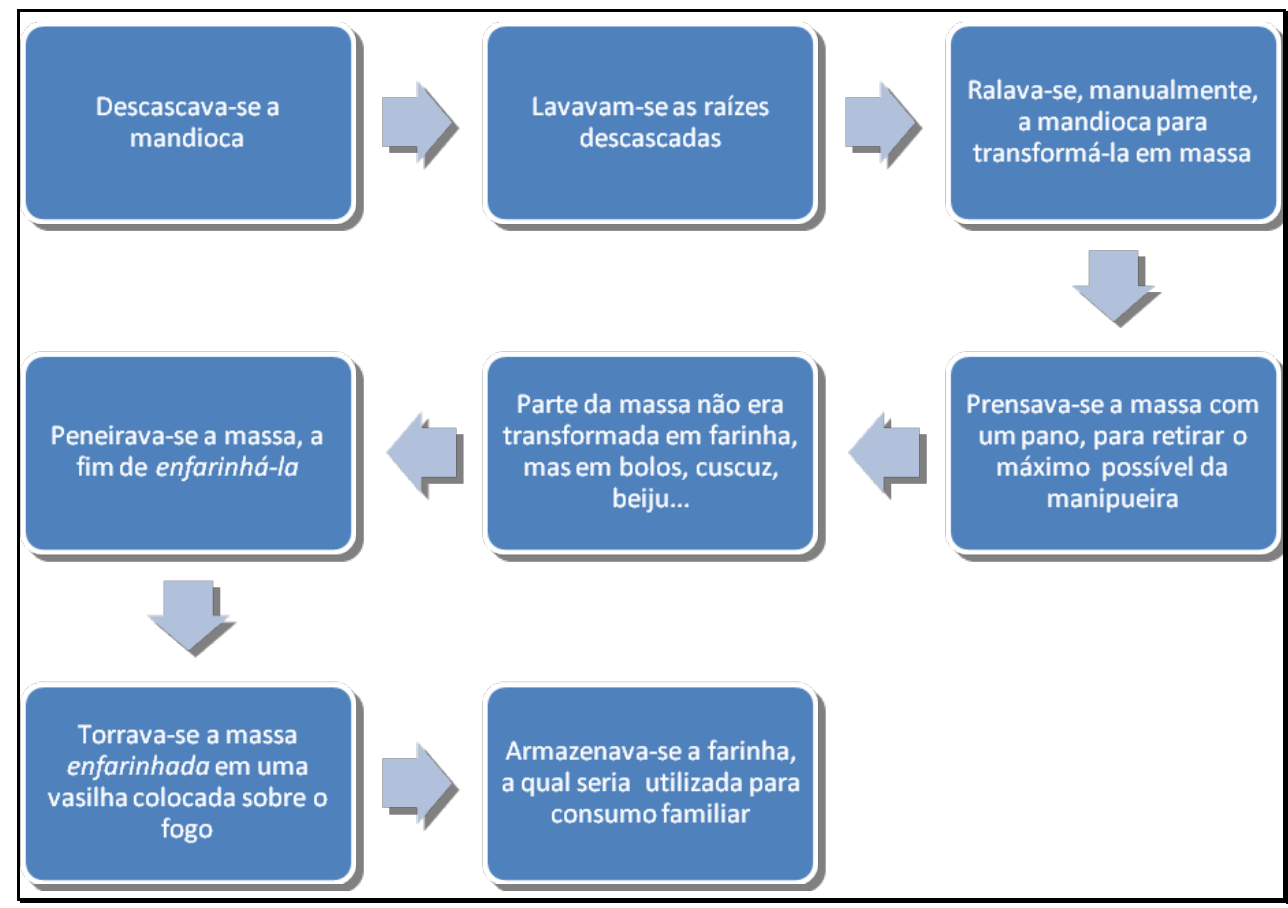

Figura 03: Como ocorria o processo de transformação domiciliar da mandioca no Agreste Potiguar, até a década de 1980 Elaboração: Diego Salomão C. O. Salvador, 2008.

No que diz respeito à transformação da mandioca nas casas de farinha (figura 04), esse processo era realizado tendo como principal fundamento o trabalho manual, a força humana. As casas de farinha eram marcadas por instrumentos técnicos movidos pela força humana (figura 05). Inicialmente, o rodete (usado para ralar a mandioca), a prensa (usada para retirar a manipueira) e a peneira (usada para enfarinhar a massa) eram instrumentos feitos de madeira; posteriormente, passaram a ser confeccionados com materiais mais resistentes, como o ferro. O forno era a braço, ou seja, construído com tijolo e cimento, aquecido com lenha, sendo a farinha mexida por um homem (o forneiro) por meio de um pedaço de madeira chamado de rodo. 


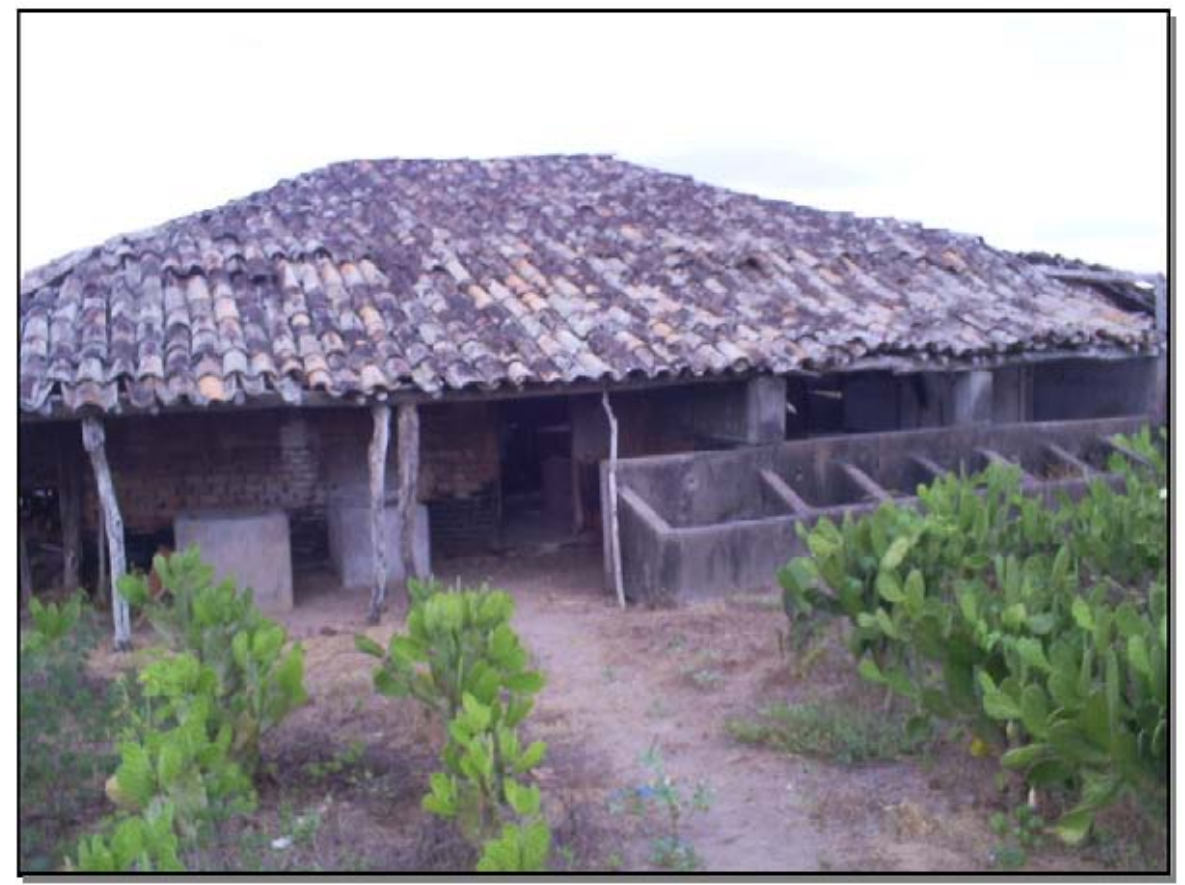

Figura 04: Casa de farinha antiga e desativada localizada em Bom Jesus Fonte: Salvador, 2008.

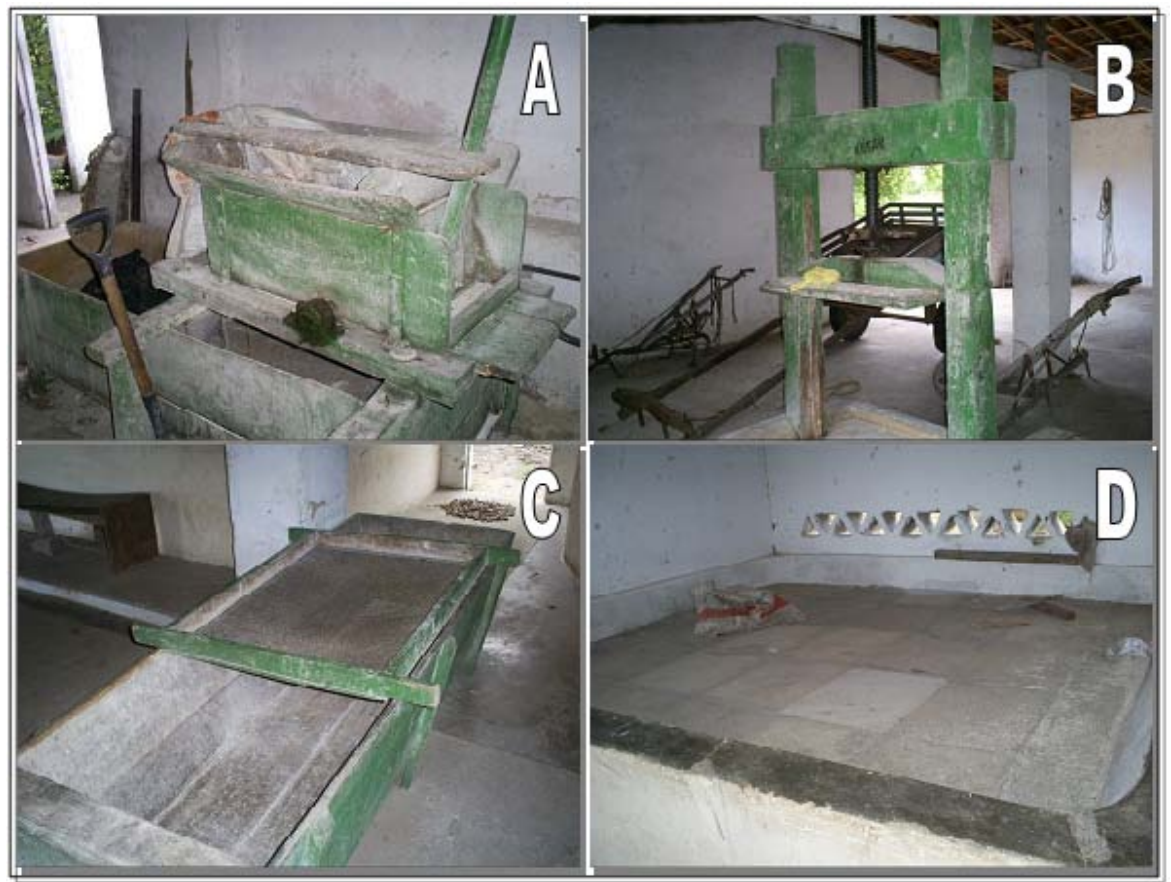

Figura 05: Instrumentos, rodete (A), prensa (B), peneira (C) e forno (D), existentes em casa de farinha do Agreste Potiguar, movidos a força humana Fonte: Salvador, 2008.

Nas casas de farinha, a fabricação da farinha ocorria da seguinte forma (figura 06): 1) as raspadeiras descascavam a mandioca; 2) lavavam-se as raízes descascadas; 3) ralava-se a mandioca no rodete; 4) tirava-se a goma da massa proveniente do rodete; 5) prensava-se a massa; 6) peneirava-se a massa; 7) torrava-se a massa enfarinhada, em um forno movido manualmente; 8) ensacava-se a farinha, que era armazenada em paióis, sendo utilizada 
para o consumo familiar; e 9) por vezes, negociava-se algum excedente da farinha produzida.

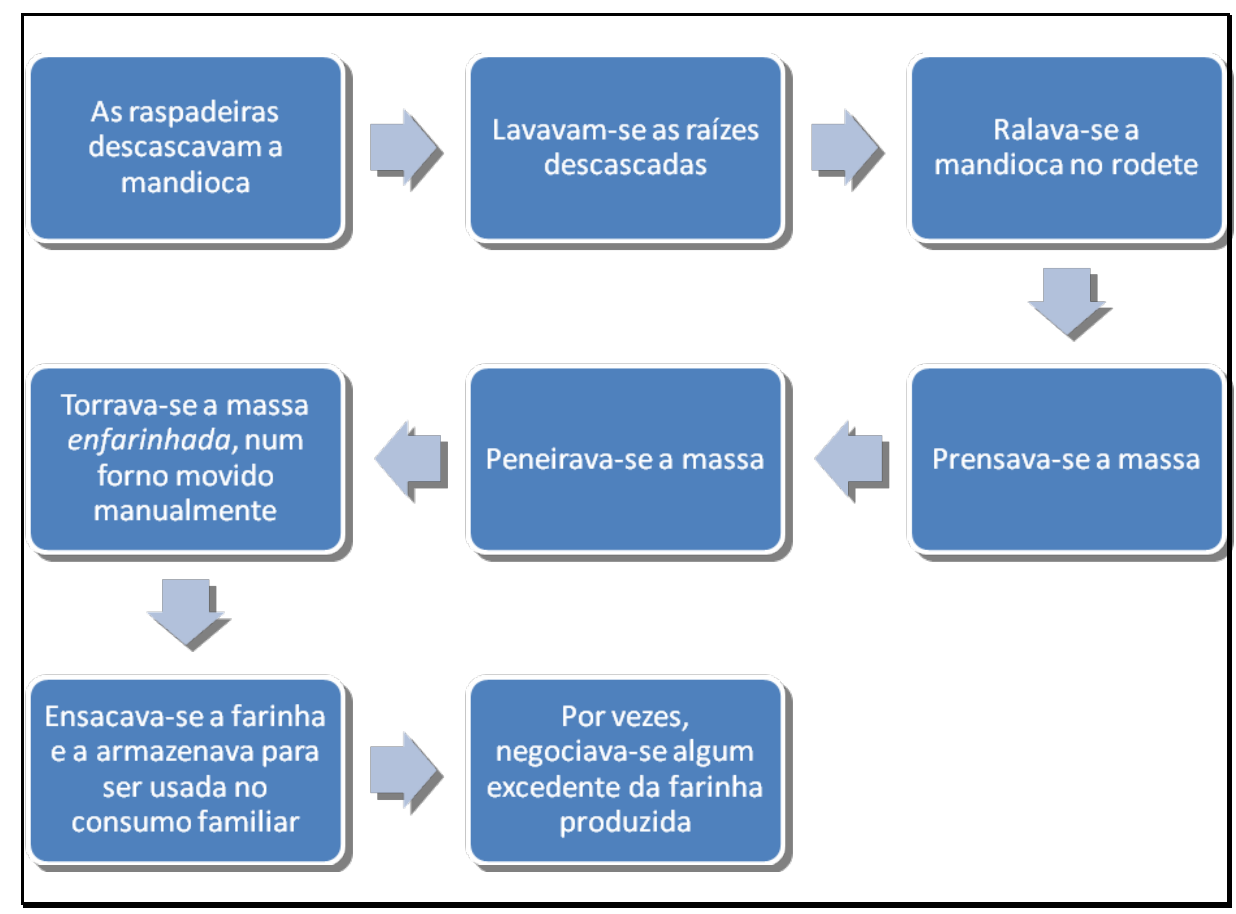

Figura 06: Como se dava o processo de transformação da mandioca nas casas de farinha no Agreste Potiguar, até a década de 1980 Elaboração: Diego Salomão C. O. Salvador, 2008.

Os proprietários de algumas casas de farinha contratavam pessoas para trabalharem no processo produtivo. Para a realização do processo, eram necessárias algumas pessoas para descascar a mandioca (o número de pessoas dependia da quantidade de farinha que se iria produzir); 01 pessoa para trabalhar no rodete; 01 na prensa e peneira; e 01 no forno e no ensacamento da farinha. Interessante é que, geralmente, o serviço de descasca era feito por mulheres e o restante dos serviços por homens. A tiragem da goma era, às vezes, realizada por mulheres e, outras vezes, pelos homens. Diante dessa divisão de gênero no trabalho, perguntamos aos produtores e donos de casas de farinha por que isso acontecia. Eles afirmaram que era porque a descasca é um serviço mais leve e para o qual as mulheres eram mais habilidosas. No entanto, o dono de uma casa de farinha de Elói de Souza nos disse que, geralmente, as pessoas que faziam o serviço de ralar, de prensar e de peneirar, e o de torrar e ensacar a farinha recebiam diárias de 5 mil réis, já as pessoas que faziam a raspagem recebiam diárias de 2 mil réis. Como vemos, deixava-se para as mulheres não apenas o serviço mais leve, mas aquele pelo qual se pagava menos. Além disso, é necessário frisar que, comumentemente, crianças trabalhavam na raspagem da mandioca, geralmente acompanhando suas mães (as raspadeiras) e seus pais (que desempenhavam os outros serviços).

Entretanto, as casas de farinha que funcionavam sob o regime de pagamento de diárias eram pouquíssimas. A grande maioria das casas de farinha eram utilizadas por famílias para fazer as chamadas farinhadas. Nessas, as famílias fabricavam uma quantidade de farinha que suprisse suas necessidades por dois anos, período máximo do ciclo de cultivo da mandioca. A farinha era guardada em locais próprios para tal finalidade, chamados de 
paióis. Algumas famílias que produziam grandes quantidades de farinha também negociavam uma parte do que fora produzido. Vejamos os detalhes que são dados por um produtor de mandioca de Bom Jesus acerca da produção e do armazenamento de farinha antigamente:

\footnotetext{
Naquele tempo se trabalhava mais por mutirão. Essa semana eu ia fazer minha farinhada, aí eu convidava os vizinhos, que se juntavam e iam ajudar minha família. Era um mutirão. A semana que vem você ia fazer a sua farinhada, aí minha família ia agora ajudar a sua. E assim por diante.
}

A farinhada, segundo Damasceno (2005), era um processo que não envolvia tão somente um conjunto de técnicas e ações sistematizadas, tendo por objetivo final a geração da farinha para a subsistência familiar. Esse processo era marcado também por relações culturais, decorrentes de tradições históricas herdadas de povos indígenas. As casas de farinha eram lugares que faziam parte da cultura do povo: lugares em que as famílias se reuniam, conversavam, contavam estórias e histórias, cantavam, dançavam etc. Seguindo essa perspectiva, Nogueira e Waldeck (2006), estudando a cultura mandioqueira no Brasil sob uma perspectiva cultural, citam as casas de farinha como espaços impregnados de significados, espaços de expressão da vida coletiva.

É necessário destacar que as casas de farinha não pertenciam às famílias pobres que faziam as farinhadas. Os donos das casas de farinha eram pessoas com melhores condições financeiras, geralmente criadores de gado e cultivadores de algodão. Para que as famílias pobres utilizassem as casas de farinha para fazer as farinhadas, era necessário pagarem a conga - uma parte do que fora produzido, a qual deveria ficar para os proprietários dessas casas. Segundo um produtor de mandioca de Serra Caiada, a cada três sacos de farinha produzidos, geralmente meio saco ficava para a casa de farinha, isto é, para seu dono. Esse meio saco consistia na conga. Um produtor de mandioca de Bom Jesus nos disse que a principal motivação para que os criadores de gado construíssem as casas de farinha era o recebimento da conga: "no período de setembro pra outubro, praticamente, todo dia tava recebendo conga do povo que fazia farinhada”. As palavras de um produtor de mandioca de Boa Saúde também indicam isso: "antigamente, as casas de farinha era tudo cheia. Era um esperando o outro acabar pra fazer a sua”. Acrescente-se o fato de ser gerada nas casas de farinha a matéria-prima para a fabricação de ração para o gado.

Por fim, frisamos que os produtores de mandioca procuravam fabricar a farinha de que necessitavam em casas de farinha próximas de sua moradia e/ou propriedade. Desse modo, podemos expressar a organização do território do Agreste Potiguar, em relação à atividade mandioqueira, da seguinte maneira: em todos os municípios havia casas de farinha e, próximas destas, havia produtores de mandioca que as procuravam para fabricar a farinha, por meio das farinhadas. A mandioca não era considerada um produto, mas sim um gênero alimentício, sumamente importante para a sobrevivência dos agrestinos.

Portanto, fica evidente que a atividade mandioqueira teve a função primordial de cultura de subsistência no processo de formação territorial do Agreste Potiguar. Outrossim, fica explícita a importância dessa atividade para a sobrevivência do povo agrestino e, consequentemente, para a formação do território em estudo. 


\section{CONSIDERAÇÕES FINAIS}

Após as abordagens colocadas em tela, afirmamos que tal cenário pretérito da atividade mandioqueira perdurou no Agreste Potiguar até meados do século XX, especificamente até a década de 1980. A partir de então, começaram a ser implementadas transformações nessa atividade, de acordo com a lógica da modernização.

De maneira breve e preliminar, frisamos que com o desencadear do processo de modernização da atividade mandioqueira, vem sendo implementadas, desde a década supracitada, mudanças nas técnicas utilizadas no cultivo e na transformação da mandioca, nas relações de trabalho entre produtores de mandioca - trabalhadores e donos de casas ou de indústrias de farinha e no uso atual do território do Agreste Potiguar, sob a perspectiva da lógica capitalista de reprodução do capital. Dentro dessa lógica, o cultivo da mandioca passa a ser feito com o uso de trator e de adubos químicos, sendo que, atualmente, a transformação desse tubérculo em farinha é realizada em casas e em indústrias de farinha, as quais vêm sendo marcadas, de modo intenso, por instrumentos técnicos movidos a eletricidade, tornando as relações de trabalho regidas, cada vez mais, pela lógica capitalista de produtividade e de exploração do trabalho. Além disso, a mandioca não é mais cultivada pelos produtores com o objetivo primordial de garantir suas subsistências alimentares, mas sim visando atender a demanda por matéria-prima das casas e das indústrias de farinha, que, por sua vez, atendem as demandas de mercados norte-rio-grandenses, pernambucanos, paraibanos e cearenses no tocante à mercadoria "farinha".

Ressaltamos que esse processo de modernização da atividade mandioqueira marca a realidade de todos os espaços em que se cultiva mandioca no Rio Grande do Norte, não se restringindo apenas ao Agreste Potiguar. Contudo, no contexto norte-rio-grandense, é nesse território que tal processo ocorre de maneira mais intensa. As maiores e mais equipadas indústrias de farinha e as casas de farinha que vêm se modernizando mais rapidamente no âmbito do estado do Rio Grande do Norte estão localizadas nos municípios de Vera Cruz e Brejinho, o que nos faz declarar que a modernização dessa atividade tenha suas maiores densidades, no tocante à produção da farinha, estabelecidas nesses municípios.

Entretanto, tais transformações explicitadas aqui de maneira preliminar, colocam em baila a necessidade de reflexões aprofundadas acerca do processo de modernização da atividade mandioqueira no Agreste Potiguar. Acreditamos que essas reflexões possam ser alicerçadas nos seguintes questionamentos: como vem ocorrendo o uso atual do território do Agreste Potiguar, considerando-se a dinâmica da atividade mandioqueira? Que mudanças técnicas e nas relações de trabalho vêm sendo implementadas, desde a década de 1980, a partir do processo de modernização da atividade mandioqueira desencadeada nesse território?

Devido a esses questionamentos nos levarem a meditações que ultrapassam os limites estabelecidos pelo objetivo do presente artigo, ressaltamos que faremos essas reflexões em um próximo artigo, que versará sobre a modernização da atividade mandioqueira no Agreste Potiguar. 


\section{REFERÊNCIAS}

1. ANDRADE, M. C. A terra e o homem no Nordeste. São Paulo: Atlas, 1986.

2. DAMASCENO, A. V. C. A cultura da produção de farinha: um estudo da matemática nos saberes dessa tradição. 2005. Dissertação (Mestrado em Educação) Universidade Federal do Rio Grande do Norte, Natal.

3. FURTADO, C. Formação econômica do Brasil. São Paulo: Editora Nacional, 1984.

4. INSTITUTO BRASILEIRO DE GEOGRAFIA E ESTATÍSTICA. Sistema IBGE de recuperação automática (SIDRA): Agreste Potiguar. Disponível em: $<$ http://www.sidra. ibge.gov.br/bda/territorio/unit.asp?codunit $=6148 \& \mathrm{z}=\mathrm{t} \& \mathrm{o}=4 \& \mathrm{i}=\mathrm{P}>$. Acesso em: 03 nov. 2009.

5. LEFEBVRE, H. La production de l'espace. Tradução do Grupo “As (im)possibilidades do urbano na metrópole contemporânea”, do Núcleo de Geografia Urbana da UFMG. $4^{\text {a }}$ Ed. Paris: Éditions Anthropos, 2000.

6. LINHARES, M. Y. ; TEIXEIRA SILVA, F. C. História da agricultura brasileira: combates e controvérsias. São Paulo: Brasiliense, 1981.

7. MELO, M. L. Os Agrestes: estudo dos espaços nordestinos do sistema gadopolicultura de uso de recursos. Recife: SUDENE, 1980.

8. MONTEIRO, D. M. Terra e trabalho na história: estudos sobre o Rio Grande do Norte. Natal: EDUFRN, 2008.

9. NOGUEIRA, M. D. ; WALDECK, G. Mandioca: saberes e sabores da terra. Rio de Janeiro: IPHAN - CNFCP, 2006.

10. SALVADOR, D. S. C. O. O território usado e o uso atual do território do Agreste Potiguar. Holos, Natal, ano 25, v. 2, p. 110-131, 2009.

11. SANTOS, M. A natureza do espaço: técnica e tempo, razão e emoção. São Paulo: Hucitec, 1999.

12. _ _ Espaço e método. São Paulo: Nobel, 1997.

13. _ Espaço e sociedade: ensaios. Petrópolis: Vozes, 1979.

14. O retorno do território. In: SANTOS, M. ; SOUZA, M. A. A. de. ; SILVEIRA, M. L. Território: globalização e fragmentação. São Paulo: Hucitec, ANPUR, 1996. p. 15-20.

15. . Por uma Geografia Nova: da crítica da Geografia a uma Geografia Crítica. São Paulo: Editora da Universidade de São Paulo, 2004. 